\title{
Modeling of the current and future potential distribution of Atlas cedar (Cedrus atlantica) forests revealed shifts in the latitudinal, longitudinal and altitudinal range towards more humid conditions
}

\author{
Abdelkrim Arar', 2, *, Yassine Nouidjem', Rabah Bounar', Slimane Tabet ${ }^{3}$, Yacine Kouba ${ }^{4}$ \\ ${ }^{1}$ Department of Natural and Life Sciences, Faculty of Sciences, University of M'Sila, \\ 28000 M'Sila, Algeria \\ ${ }^{2}$ Laboratoire de Biologie, Eau et Environnement [LBEE), Faculty of SNV-STU, University of 8 may 1945, \\ Guelma, Algeria. \\ ${ }^{3}$ Department of Natural and Life Sciences, Institute of Technology, University of Abdelhafid Boussouf, \\ 43012 Mila, Algeria \\ ${ }^{4}$ Department of Geography and Land Planning, University of Larbi Ben M'hidi, \\ 04000 Oum-El-Bouaghi, Algeria \\ *corresponding author email: abdelkrim.arar@univ-msila.dz \\ Received: 19 February 2020 / Accepted: 10 April 2020
}

\begin{abstract}
Environmental forcing affects biodiversity in some parts of the biosphere where many sensitive species, including endemic and rare species, respond through changes in their geographical distribution. Modelling of spatial dynamics of species is crucial to advance our understanding of species' adaptive behaviour and sensitivity to environmental changes and forcings.

The present study aimed at assessing suitable habitats of the Atlas cedar (Cedrus atlantica) in North Algeria for the current period (1990-2000) and predicting its future range in 2050 and 2070, following climate warming scenarios. The Maximum Entropy (MaxEnt) model was used to model the present and future potential distribution of Atlas cedar forests. A total of 1328 occurrence records obtained from field surveys and 50 environmental variables were used. These variables included 19 climatic variables (WorldClim database), 21 edaphic proprieties (SoilGrids database), and 10 topographic traits (retrieved from a $30 \mathrm{~m}$ digital elevation model). MaxEnt showed high predictive power with a significant value of Area Under Curve $(\mathrm{AUC}=0.988)$. Potential distribution of Cedrus atlantica forests for the present period was confined to mountain areas (predicted potential range size $=2089 \mathrm{~km}^{2}$ ). Environmental factors with the highest percentage of contribution included: soil total nitrogen (22.2\%), elevation (20.5\%), mean temperature of the most humid quarter 'Bio8' (18.8\%), slope $(12.9 \%)$, soil total carbon $(10.3 \%)$, and precipitation of the driest month 'Bio14' $(3.4 \%)$. The species range is expected to reduce significantly under future climate change scenarios (decline of about $70.4-80.6 \%$ of its current potential distribution), with a shift towards more humid conditions, in this case to the north and east towards more humid climates and mesic habitats. The predicted shifts in the altitude gradient follow in the direction of higher elevations, with the disappearance of cedar forests at low altitudes. This indicates that the identified Atlas cedar refugia resulting from climate change are determined by humidity. Our findings provide information on the magnitude of environmental forcings that seriously threaten Cedrus atlantica forests in drought-prone areas in North Africa. It is therefore necessary to implement effective strategies to preserve and protect more sensitive forests.
\end{abstract}

Keywords: North African forests, SDM, Cerdus atlantica, environmental forcings, forest dieback, range shift, climate warming. 


\section{Introduction}

Habitat suitability models or ecological niche models, called Species Distribution Models (SDMs), are robust tools used in macroecology, ecology and biogeography (Booth et al., 2014; Graham \& Kimble, 2019). SDMs are methods used to evaluat areas that provide appropriate abiotic environments (often the climatic niche) for a given species or taxa, using the relationship between the observed species/taxa presence points and the associated environmental conditions. The ultimate aim of SDMs is provide spatial predictions of areas in which environmental conditions are favorable for species survival and development (Elith et al., 2011; Booth et al., 2014). Currently, SDMs are multi-purpose; they can be used in rehabilitation, management or reintroduction of endemic species threatened by extinction (Fois et al., 2016). SDMs are powerful decision-making tools for predicting landuse change and assessing the impact of global warming on species. They also assist in planning of nature conservation programs and reintroduction of endangered species (Amici et al., 2017; Safaei et al., 2018). The role of ecological niches is pivotal in explaining the persistence of species competitive ability and geographical distribution (Silvertown, 2004). Climate, edaphic characteristics, topography and biological interactions are the main factors that define species distribution and ecological niche (Chenchouni, 2017; Wan et al., 2019).

Since is expected that the temperature will increase globally by $4.8^{\circ} \mathrm{C}$ in 2100 (IPCC, 2014), the quantification of global warming impacts on ecosystems is one of the biggest scientific challenges today (Walther et al., 2002; McDowell \& Allen, 2015; Zhang et al., 2019). Climate change can lead to modify the geographic range distribution of many species (Gonzalez et al., 2010). Particularly, endemic and endangered species, which distribution range is limited and are adapted to particular environmental conditions, could extinct under the effects of climate change (Fois et al., 2016; Abel-Schaad et al., 2018). Because of their extremely restricted habitats, many endemic species are threatened by extinction, and are listed on the IUCN Red List, as is the case of the Atlas Cedar (Cedrus atlantica (Endl.) Manetti ex Carrière) (Thomas, 2013). Hence, the identification of the current geographical distribution and the threats that expose endemic taxa to the risk of extinction constitute the first step to launch a conservation strategy (Booth et al., 2014; Cheddadi et al., 2017; Safaei et al., 2018). The widespread decline of forests in various ecosystems and biomes is mainly linked to climate change (Allen et al., 2010; Choat et al., 2012; McDowell \& Allen, 2015). In NW Africa, where drought is expected to intensify (Knippertz et al., 2003; Zeroual et al., 2019), forest ecosystems are vulnerable to biome change under the climate change scenarios projected by the IPCC (Tabet et al., 2018).

The Atlas Cedar is an endemic species to mountains from Algeria and Morocco, where represents a keystone component of North African forests (Quézel, 1998; Cheddadi et al., 2009, 2017; Linares et al., 2011; Bouahmed et al., 2019). In Algeria, the species occurs in mountains of the Tellian and Saharan Atlas, where it has a scattered distribution controlled mainly by climatic and orographic traits (Quézel, 1998; Slimani, 2014). This species occurs at elevations between c. 900 and $2200 \mathrm{~m}$ a.s.l., where the minimum temperature of the coldest month ranges between -1 and $-8^{\circ} \mathrm{C}$, the amount of annual rainfall ranges from c. 500 to $2000 \mathrm{~mm}$, and the species can resist to temperatures ranging from $-20^{\circ} \mathrm{C}$ to $+39^{\circ} \mathrm{C}$. Under water stress, Atlas Cedar maintains its physiological activity up to very pronounced drought levels (Khanfouci, 2005; Thomas, 2013). Given its resilience and indifference to lithological substratum, the species occurs on diverse substrates and soils. However, Cedar forests are subject to the threats of global warming despite that this species has relatively wide tolerances towards to climate and soil type. (Chenchouni et al., 2008; Cheddadi et al., 2017). The current state of the Algerian Atlas Cedar forests reflects episodes of dieback and mortality which are mainly related to unfavorable climatic conditions (Chenchouni, 2010), marked by severe episodes of droughts since the 1980s (Touchan et al., 2011). As a result, the adaptive capacity of some Atlas Cedar populations has reached a critical limit, which led to their irreversible degradation (Slimani, 2014; NavarroCerrillo et al., 2019). Future predictions have shown an altitudinal refuge of Atlas Cedar forests to the mountain peaks, with high risk of stand extinctions at lower altitudes and drier conditions (Cheddadi et al., 2017; Abel-Schaad et al., 2018; Arar et al., 2019; Bouahmed et al., 2019).

The current study aims at (i) predicting the current potential distribution of the Atlas Cedar in Algeria using several environmental variables related to climate, soil and topography, (ii) identifying the key environmental factors that shape its current suitable geographic range, and (iii) estimating the possible impact of climate change on species distribution range and quantifying habitat loss in order to assist to decision makers to take appropriate planning measures for the conservation of Atlas Cedar forests. In addition, we assume that Cedrus atlantica distributional range decreases in the future due to further negative effects of climate change that already induced species forest mortality in many locations of its range ( $c f$. references cited above). Thus we hypothesize that this range shrinkage is associated with spatial shifts towards habitats that offers suitable conditions, which are expected to match habitats in high altitudes with mesic conditions. Thus species range shifts in Algeria are projected to occur along a latitudinal gradient from south to north, from west to east (toward 
wetter climates), and with decreasing of aridity (drought duration and intensity).

\section{Materials and methods}

\subsection{Study area}

The study area comprises the northern part of Algeria that covers $488,457 \mathrm{~km}^{2}$, that located between the meridians $2^{\circ} 13 ' 4.8^{\prime \prime}$ West and $8^{\circ} 40^{\prime} 59.52^{\prime \prime}$ East and parallels $32^{\circ} 58^{\prime} 31.08^{\prime \prime}$ North and $37^{\circ} 5^{\prime} 31.2^{\prime \prime}$ North. It is limited from the East and West by the Tunisian and Moroccan borders, respectively, and from the south by the Sahara Desert and from the North by the Mediterranean Sea (Fig. 1). The area includes two mountain ranges (Tellian Atlas and Saharan Atlas) that stretch from the East to the West of the country. This topographical organization divides the study area into five large spatial units (Fig. 1) with different landscapes, geomorphology, climate and vegetation; viz. (i) the Tellian system in the North, it plunges towards the Mediterranean Sea and has a humid Mediterranean climate characterized by dry summers and rainy winters (annual precipitation $=300-1200 \mathrm{~mm}$ ), (ii) the Tell Atlas Range, (iii) Steppe rangelands of the High Plains with semi-arid climate, (iv) The Saharan Atlas Range, and (v) a part of the Sahara Desert characterized by low precipitation $(<100 \mathrm{~mm})$ and large inter-annual variability. Within the ranges of Tellian Atlas and Saharan Atlas, the Atlas Cedar occurs naturally in the mountains of Aurès, Belezma, Hodna, Djebel Babor, Djurdjura, Blida and Ouarsenis (Thomas, 2013; Slimani, 2014). Based on natural species range distribution, we selected the whole part of northern Algeria to model Atlas Cedar potential distribution.

\subsection{Species occurrence data}

Global positioning system (GPS) occurrence records of Atlas Cedars were collected in 2017 over its geographic range distribution in Algeria. for inaccessible Atlas Cedar forests, Google Earth was used for the identification and localization of species occurrence points. Clustered samples were removed from the geodatabase and only one record per grid cell (pixel of $1 \mathrm{~km}^{2}, c f$. subsection: 2.3. Modeling procedure) was used in order to avoid overrepresentation of environmental conditions in densely sampled areas (Zhang et al., 2019). In total 854 occurrence records of Atlas Cedar were used in modeling analysis in the study.

\subsection{Environmental data}

Considering the biological relevance and data availability under current and future climate scenarios, a total of 32 environmental variables, including three groups of data (climatic, edaphic, topographic), were used in modeling present and future potential distribution of Atlas Cedar

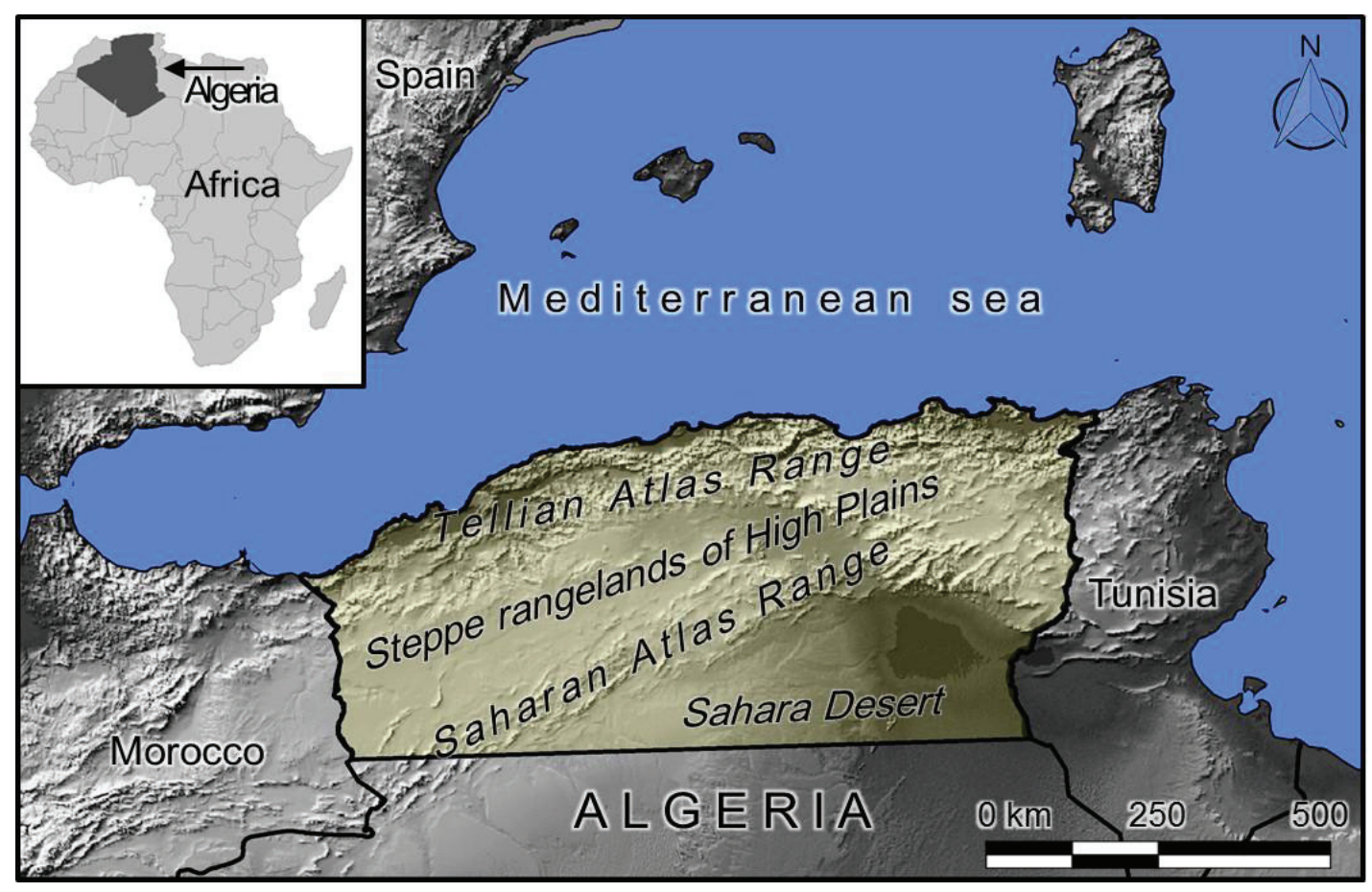

Figure 1. Geographic location of the study area in Algeria, North Africa 
forests. These 32 variables were selected from 19 climatic variables, 21 edaphic proprieties, and 10 topographic traits, after testing collinearity between variables using Pearson correlation tests. Before any model execution, predictive variables having a significant linear relationship with other environmental variables were excluded from the model in order to ensure a high validity of the results. It is noteworthy to mention that no prohibitive levels of redundancy existed between layers of selected environmental variables, i.e. all pairwise Pearson's correlation coefficients were less than $|0.8|$. The choice among correlated variables was done based on their importance role in matching species ecophysiological needs (Guisan \& Zimmermann, 2000; Williams et al., 2012) .

Climate data were obtained from WorldClim (http:// worldclim.org/version1: Hijmans et al., 2005) and comprise nine bioclimatic variables, named: mean diurnal range (mean of monthly ( $\max$ temp - min temp)) 'Bio2', isothermality 'Bio3', temperature seasonality 'Bio4', min temperature of coldest month 'Bio6', mean temperature of wettest quarter 'Bio8', mean temperature of driest quarter 'Bio9', precipitation of driest month 'Bio14', precipitation seasonality 'Bio15', precipitation of wettest quarter 'Bio16'. It is noteworthy mentioning that climatic variables were selected for three periods: current (1950-2000) and two future scenarios 2050 year and 2070 year (Hijmans et al., 2005). Future data were determined based on two representative concentration pathways (RCP) of greenhouse gas concentration trajectory: RCP4.5 is an intermediate emission scenario with medium greenhouse gas concentrations and RCP8.5 is a pessimistic scenario with high concentrations (IPCC, 2014).

Edaphic data were obtained from global SoilGrids (https://soilgrids.org) and included 17 variables viz. clay content $[\%]$, sand content $[\%]$, soil total carbon 'CTO' $[\mathrm{g} / \mathrm{kg}]$, soil total nitrogen 'NTO', carbon to nitrogen ratio ' $\mathrm{C} / \mathrm{N}$ ', four exchangeable cations $\left(\mathrm{Ca}^{++}, \mathrm{Mg}^{++}, \mathrm{Na}^{+}\right.$and $\left.\mathrm{K}^{+}\right)$, electrical conductivity 'EC', cation exchange capacity 'CEC', bulk density $\left[\mathrm{kg} / \mathrm{m}^{3}\right], \mathrm{pH}$, porosity [\%], and base saturation (total exchangeable bases/CEC) [\%]. Furthermore, climatic and edaphic data from WorldClim and soilgrids databases, respectively, were used for computing soil available water capacity of summer 'AWC_Summ' and spring 'AWC_Spr' for the period of 1950-2000 and the future projections 2050 and 2070 (Tabet et al., 2019).

Topography-related data were derived from the Global Digital Elevation Model of ASTER GDEM version 2 (https://asterweb.jpl.nasa.gov/gdem-wist.asp). A total of 6 variables were employed in modeling, viz. elevation [m a.s.1.], slope [\%], aspect, global theoretical radiation of summer $\left[\mathrm{Wh} / \mathrm{m}^{2}\right]$, global theoretical radiation of spring $\left[\mathrm{Wh} / \mathrm{m}^{2}\right]$, and distance to the sea $[\mathrm{km}]$.

\subsection{Modeling procedure}

Among the most common problems in SDMs is the spatial autocorrelation of environmental variables. Spatial autocorrelation occurs when spatialized variables are dependent on each other, all the more strongly as the locations are closer (Legendre \& Fortin, 1989). In the present study we examined the spatial autocorrelation in the Atlas Cedar occurrence map using Moran's I correlogram (Legendre \& Legendre, 1998). Moran's I correlogram showed a disappearance of spatial autocorrelation at a distance of $1 \mathrm{~km}$ among occurrence records, therefore all layers were resampled to a spatial resolution of $1 \mathrm{~km}$.

To predict the potential distribution of Atlas Cedar, an algorithm with automatic learning called the Maximum Entropy method "MaxEnt" version 3.4.1 was used (Phillips et al., 2006). Like any statistical model, assessing the relevance and performance of the used model is unavoidable and necessary in order to check the validity of the results and to confirm whether the predictions are correctly calculated (Guisan et al., 2017). Accordingly, the predictive performance of the model was evaluated by calculating the AUC through validation with 10 repetitions. In this approach the dataset was randomly divided into 10 groups with equivalent number of distribution records, of which nine groups were used to train the model' and one was kept for comparison with the predictions 'test data'. The resulting AUC value was then the average of the 10 tests (Guisan et al., 2017). AUC values typically range from 0 to 1 , with 1 representing maximum performance. The final mapping of the potential species distribution was represented as spatialization of occurrence probability values ranging from 0 to 1 (Phillips et al., 2006). The contribution of each variable to the predicted model was also calculated as average of 10 repetitions. The response curves of the species with regards to each environmental variable have been plotted and represented, these curves correspond to the variations in the probabilities of occurrence of the species as a function of the gradient of each predictive variable.

\subsection{Assessing species range shift}

Primarily, the current and projected climatic conditions (i.e. drought severity) of the Atlas Cedar range were determined by computing De Martonne aridity index, using climate data (mean annual temperature and total precipitation) of the current period (1950-2000) and those of RCP4.5 and RCP8.5 for the years 2050 and 2070. The possible shift in Atlas Cedar range under future climate scenarios (i.e. RCP4.5 and RCP8.5 for the years 2050 and 2070) was assessed selecting from the maps produced for each scenario and from the current potential distribution; 1 the pixels with high potential of occurrence (probability of occurrence $\geq 0.6$ ). For each pixel, its longitude, latitude, 
altitude and aridity index values were extracted. The variations in longitude, latitude, altitude, and climatic conditions between the selected pixels from each scenario-map and those of the current potential distribution were tested using non-parametric Kruskal-Wallis one-way ANOVA test. In addition, Dwass-Steel-Crichtlow-Fligner test was used for pairwise comparisons. The analyses were carried out using the function 'ggbetweenstats' of the package \{ggstatsplot\} in R (Patil \& Powell, 2018).

\section{Results}

\subsection{Model accuracy}

Based on the 10 repetitions ( $90 \%$ of training data and $10 \%$ for testing data), the constructed model converged after 5000 iterations and revealed that the area under the curve (AUC) was 0.988 . This value indicated high quality of the model fit, thus the model was considered the most successful with best fit (Fig. 2). The AUC value can be interpreted as the ability of the model to discriminate between species presence and absence, which was determined through the Receiver Operating Characteristic (ROC) curve. The latter relied on the estimation of the probability when the model correctly classified a true presence (sensitivity) and a true absence (specificity). The significance of this curve was quantified using the AUC based on 10 repetitions for an average omission rate. Values close to 0.5 indicated a random fit (occurrence by chance), while a value of 1.0 indicated a perfect fit, which was the case of the current study (0.988). If values were less than 0.5 , this indicates that the model fit was worse than random.

\subsection{Effects of environmental variables}

The response curves obtained represented the effects of the three categories of environmental variables tested on $\mathrm{Ce}$ drus atlantica distribution. The most important variables explaining the presence of Cedrus atlantica were, sorted by order of contribution: soil total nitrogen with the highest contribution $(22.2 \%)$ among all the tested parameters, followed by the altitude $(20.5 \%)$, then mean temperature of the wettest quarter 'Bio8' (18.8\%), slope (12.9\%), soil total carbon (10.3\%), and precipitation of driest month 'Bio14' $(3.4 \%)$ (Fig. 3$)$. The rest of the variables tested have minor effects with negligible contributions in the model, where the sum of contributions of all these 26 variables totaled only $11.8 \%$ (Appendix Table S1). Soil total nitrogen, slope $(<40 \%)$, soil total carbon and Bio 14, have a positive effect on the spatial distribution of Cedrus atlantica. This means that species occurrence probability increased when values of the former variables increased. However, altitude, slope ( $>40 \%$ ), Bio8 had a negative effect on species occurrence probability (Fig. 3).

\subsection{Species range prediction and change}

The mapping of Cedrus atlantica potential distribution based on occurrence probabilities showed that favorable habitats were fragmented and scattered over the entire study area in northern Algeria. Species range distribution occupied an area of $2089 \mathrm{~km}^{2}$ which is $0.43 \%$ of the total study area. In the current period (1950-2000), high potential occurrence areas occurred mainly in eastern of Algeria, occupying high altitudes of the montane regions (Fig. 4).
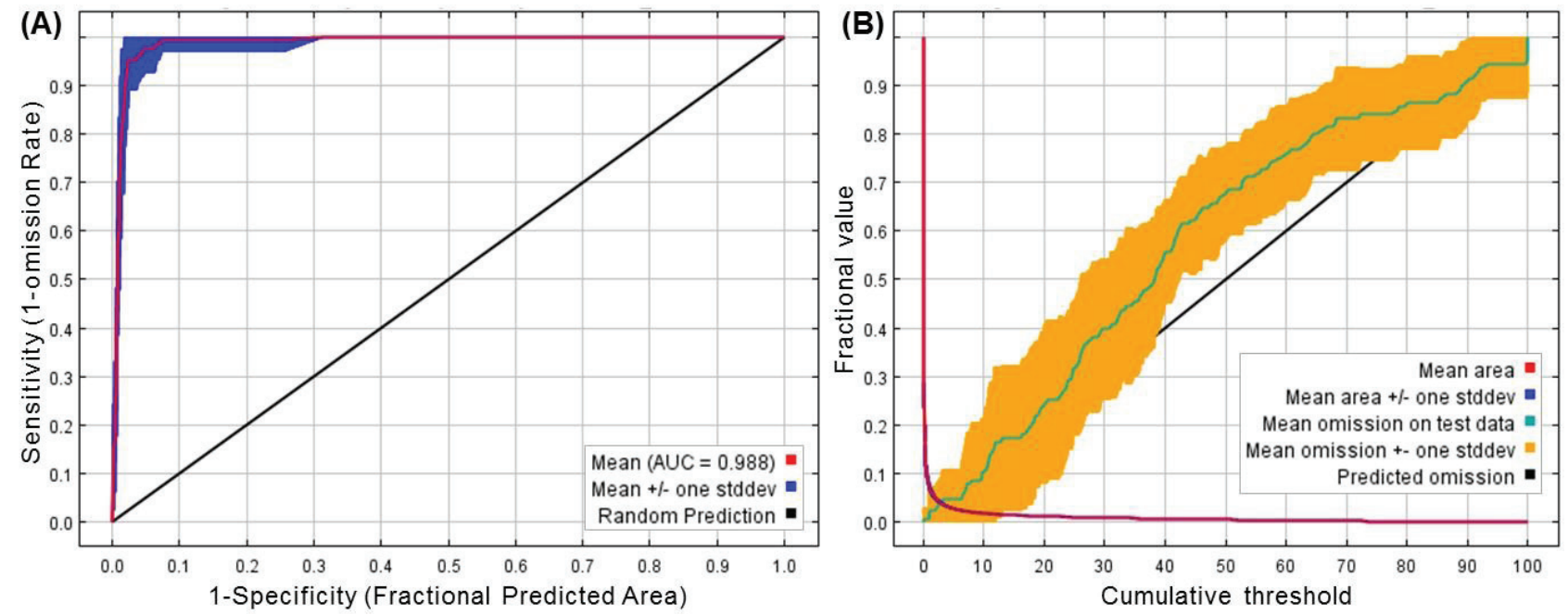

Figure 2. MaxEnt receiver operating characteristic (ROC) curve indicating AUC of training and test prediction data (A). Average omission rate of tested and predicted Cedrus atlantica suitable areas (B) 

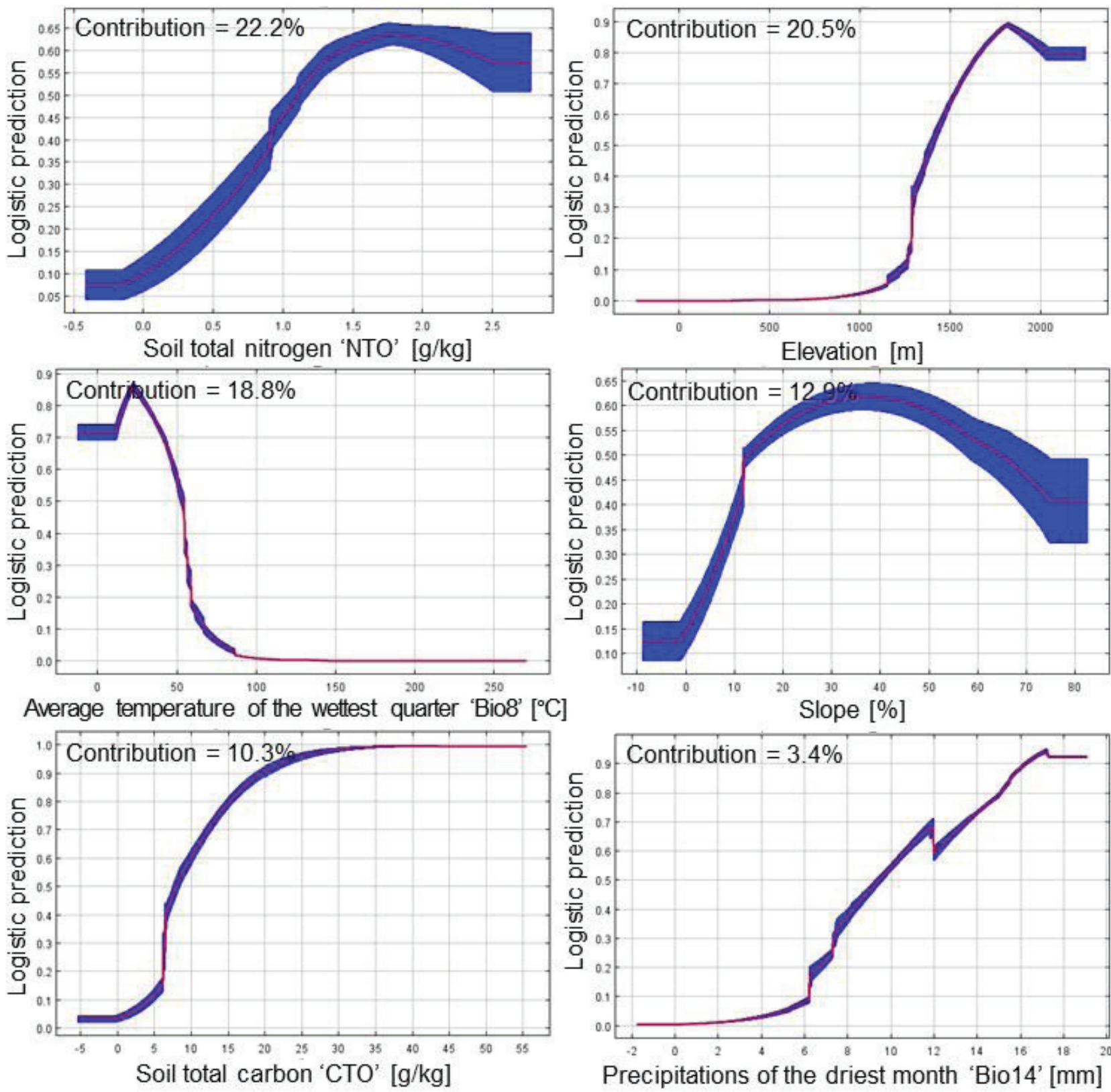

Figure 3. Response curves of Cedrus atlantica to the six most contributing environmental variables in species distribution modeling ( sum of contributions $=88.2 \%$ ). The value shown on the $\mathrm{y}$-axis (i.e. logistic prediction) is predicted probability of suitable conditions, as given by the logistic output format, with all other variables set to their average value over the set of presence localities. The contribution of each variable (in \%) to the predicted model is the average of 10 repetitions. Contributions of all tested environmental variables are reported in Appendix Table S1.

The model provided the future potential distribution of the species for both years 2050 and 2070 projections, which allowed to perform comparison tests to assess changes in areas of the favorable habitats over time. The results obtained here were consistent with our assumptions about the distributional area undergoing significant shrink- age for both future climate change scenarios. The degradation of Atlas Cedar range size is expected to be catastrophic in the future. For the pessimistic scenario 'RCP 8.5', species range is predicted to decreased in 2050 by $76.3 \%$ of the present suitable area, to reach by 2070 an area of $406 \mathrm{~km}^{2}$ of suitable habitats, which represented $80.6 \%$ of 


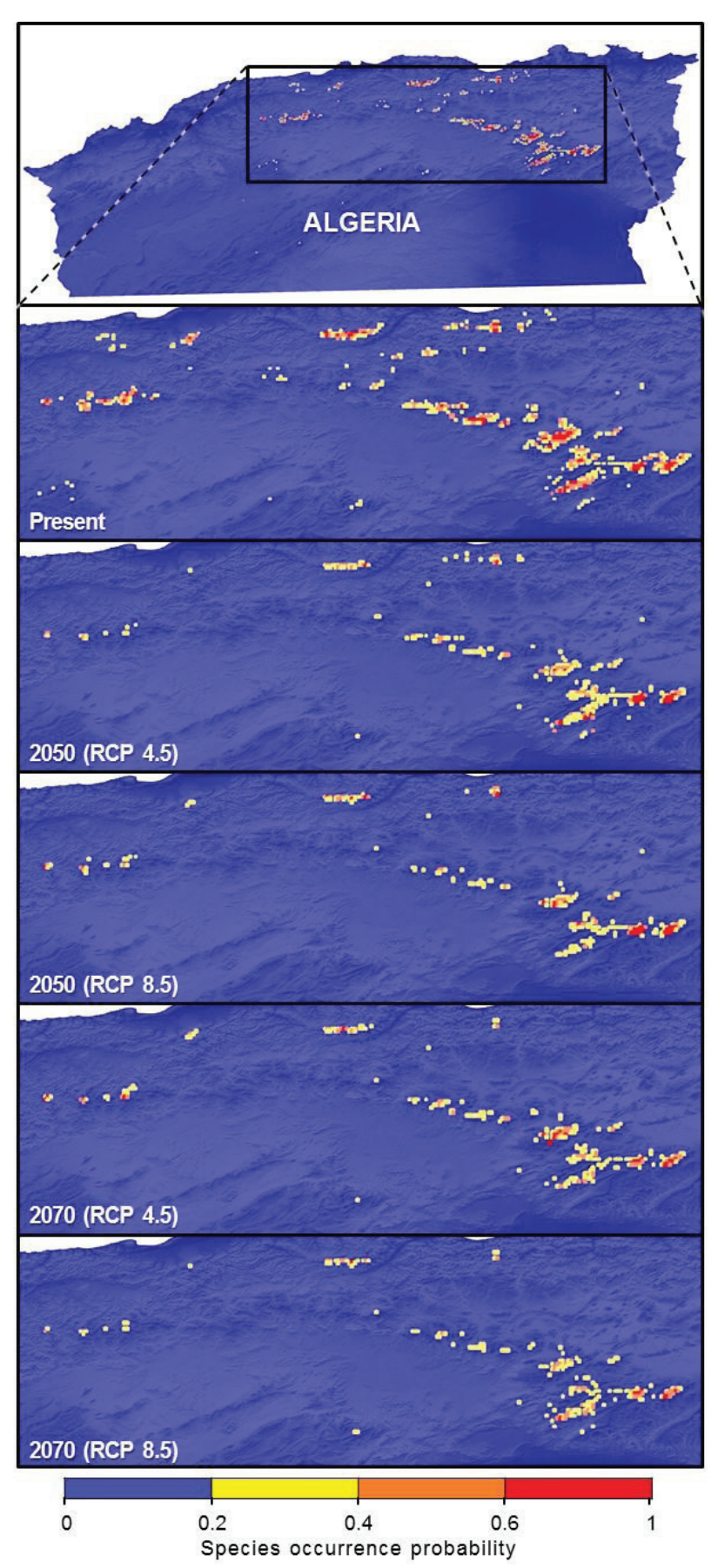

Figure 4. Predictive maps of Cedrus atlantica potential occurrence probabilities for the current period (1990-2000), 2050 and 2070 under RCP4.5 and RCP 8.5 scenarios

decline in Atlas Cedar forests of Algeria. Species regressions under the moderately optimistic scenario 'RCP 4.5' were not less bad than the previous projections for RCP8.5. The area of Atlas Cedar forests is estimated to decline by
$70.4 \%$ in 2050 and $71.6 \%$ in 2070 to reach $619 \mathrm{~km}^{2}$ and $594 \mathrm{~km}^{2}$, respectively (Table 1).

Table 1. Projected changes in range size of Cedrus atlantica under future climate scenarios in 2050 and 2070 based on two representative concentration pathways (RCP4.5 and RCP8.5) of the IPCC (2014)

\begin{tabular}{|c|c|c|c|c|}
\hline Period & $\begin{array}{c}\text { IPCC } \\
\text { scenarios }\end{array}$ & $\begin{array}{c}\text { Range size } \\
{\left[\mathrm{km}^{2}\right]}\end{array}$ & $\begin{array}{c}\text { Change } \\
{\left[\mathrm{km}^{2}\right]}\end{array}$ & $\begin{array}{c}\text { Change } \\
{[\%]}\end{array}$ \\
\hline Current & - & 2089 & - & - \\
\hline 2050 & RCP 4.5 & 619 & -1470 & -70.4 \\
\hline 2050 & RCP 8.5 & 518 & -1571 & -76.3 \\
\hline 2070 & RCP 4.5 & 594 & -1495 & -71.6 \\
\hline 2070 & RCP 8.5 & 406 & -1683 & -80.6 \\
\hline
\end{tabular}

Future forecasts predicted for all RCP 4.5 and 8.5 scenarios for the years 2050 and 2070, showed significant decreases in Cedrus atlantica ranges, particularly in the western part of the study area. The comparisons of elevation, latitude, longitude and aridity index values between occurrence probability maps indicated a change in species range distribution that results in a refuge for the species at high altitudes associated with latitudinal and longitudinal shifts to the North and East of the area study, respectively (Fig. 5).

\section{Discussion}

Using species distribution modelling approach, the current study presented the potential spatial distribution of Atlas Cedar forests in Algeria inferring the main environmental variables that influence its potential distribution. The study also predicted current and future species distributional niche based on future climatic warming conditions projected by the IPCC (2014). SDM results provided valuable information on the vulnerability of the Atlas Cedar to future changes in environmental conditions of its actual habitats. Our findings stress that Atlas Cedar populations located in areas with drier conditions or that in the future potentially will be exposed to droughts are the most sensitive and prone to local extinction. The species range is predicted to shrink with shifts towards wetter conditions, in our case northward to mesic coastal areas and altitudinally toward high elevations. SDM, such as MaxEnt, is therefore a powerful tool that significantly help to the understanding of ecological requirements of living organisms and for the prediction of spatial distribution of suitable habitats at various spatial and temporal scales (Booth et al., 2014; Guisan et al., 2017; Graham \& Kimble, 2019). 

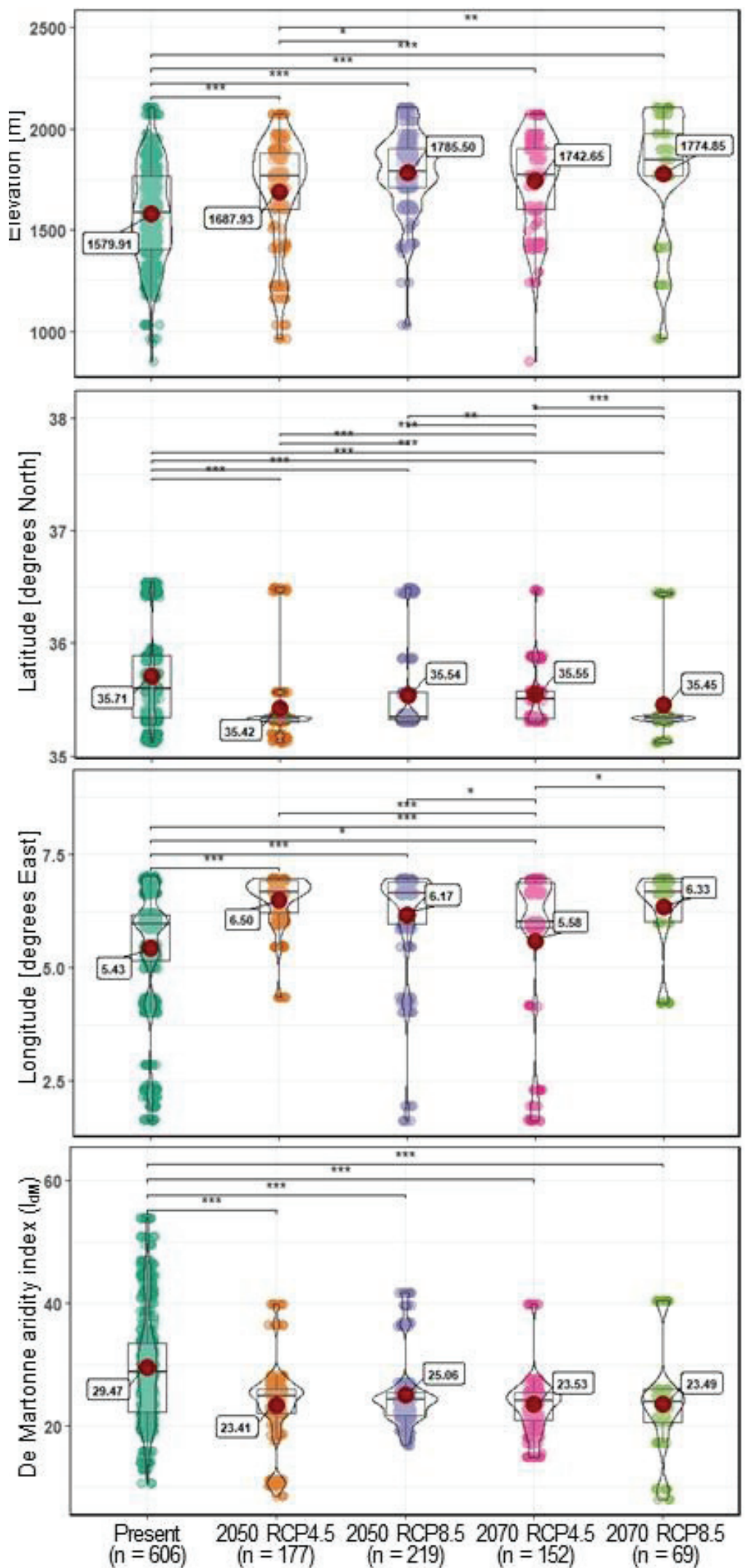

Figure 5. Pirate plots comparing altitude, latitude, longitude and aridity index values of Cedrus atlantica range between the current potential distribution and each of the future scenarios 2050 and 2070 for RCP4.5 and RCP8.5 
Characterized by intense and long periods of drought and high temperature in summer that can reach damaging thresholds, the climate of the Mediterranean basin become increasingly severe, which can affect physiological processes of trees and therefore lead to species loss and large regression in forest areas (Allen et al., 2010; Choat et al., 2012). Results of our survey revealed through species response curve to the temperatures of the wettest season, that Atlas Cedar persists up to $+6^{\circ} \mathrm{C}$, from which the probability of species occurrence begins to decline sharply until it disappears. In addition, the response curve to the precipitation of the driest month shows a positive response of cedars to water availability. Previous studies revealed that water absorption during summer in the Atlas Cedar can reach up to $20 \mathrm{~mm}$ per month (Quézel, 1976; Aoubouazza, 2018).

Atlas Cedar prefers humid areas with cold winter and it is highly vulnerable to high temperatures during this season (Quézel, 1976). Frost play important role in cedar regeneration because it triggers cone disarticulation and influences seed dispersal success. Thus, the increase in winter temperatures affects directly and negatively the regeneration and sustainability of Atlas Cedar stands (Ezzahiri \& Belghazi, 2000; Hansen et al., 2018). Temperature and precipitations are considered as determining factors of species spatial distribution, each species has its threshold of tolerance with respect to these climatic factors. Several studies highlighted that climate warming and depletion of soil water reserve are the main causes of tree loss and forest dieback (Allen et al., 2010; Choat et al., 2012; NavarroCerrillo et al., 2019). Physiologically, the availability of water directly affects seedling emergence and plant growth (Khanfouci, 2005; Aoubouazza, 2018).

Climate change forecasts in North Africa stress rising of temperature and decreases in rainfall (Zeroual et al., 2019), which might lead in the future to shrinkage of species range and/or northward shift to more suitable favorable conditions (Malcolm et al., 2006; Gonzalez et al., 2010; Garcia et al., 2012; Tabet et al., 2018). Likewise, the long and intense periods of drought associated with warm stress could greatly alter the structure, composition and geographical distribution of forests resulting in significant mortality, especial in forests located in drought prone areas (Gonzalez et al., 2010; Linares et al., 2011). Recent studies suggest that these severe environmental changes, if keep worsening with same pace and trend, could lead to the extinction of the Atlas Cedar in the future (Arar et al., 2019; Bouahmed et al., 2019). Already, the situation of Atlas Cedar forests in almost all North African populations is alarming and requires urgent actions (Chenchouni, 2010; Thomas, 2013; Cheddadi et al., 2009, 2017; Linares et al., 2011; Abel-Schaad et al., 2018; Navarro-Cerrillo et al., 2019).

In montane landscapes, topographic features such as altitude, slope and aspect make forests more sensitive to environmental changes along the ecological gradients created along narrow altitudinal zones (Rhanem, 2010). Atlas Cedar stands occurring in low elevations are the most vulnerable to dieback, which affecting both young seedlings as well as old trees. In these areas, seed dispersal, seeding and regeneration of cedars is easier than in high altitudes, however the delay in the vegetative period caused by prolonged and/or severe water stress can lead to the mortality of young cedars because their root system is not sufficiently developed (Ezzahiri \& Belghazi, 2000; Khanfouci, 2005; Navarro-Cerrillo et al., 2019).

Several landscape-related factors aggravate the risk of deterioration of montane cedar forests, which most often occur on steep slopes and rugged terrains. According to Atlas Cedar response curve to slope (Fig. 3), the suitable habitats have slope $<40 \%$. Steeper slopes increase the risk of water erosion that transports both all kinds of breeding materials (i.e. seeds and cones) thus decreasing the chance of regeneration, and soil particles, which expose surficial roots, mainly of young seedlings, to air and dryness which trigger their mortality (Khanfouci, 2005). Water erosion in steep slopes with shallow soil reduces the level of litter deposited and hinders carbon and organic matter turnover, which affect plant nutrition as soil fertility deteriorates. Indeed, sufficient level of organic matter in the soil is considered the key indicator of forest soil quality (Sequeira \& Alley, 2011). Likewise soil carbon content and nutrient dynamics have a significant relationship with forest degradation (Wan et al., 2019). The response curves obtained show high contributions of total carbon and total nitrogen to spatial distribution of Atlas Cedar, which expressed an exponential increase of the occurrence probability with the increase of $\mathrm{C}$ and $\mathrm{N}$ concentrations. The growth and ramification of the root system is highly associated with the availability of nitrogen in soil. Indeed, the relationship between nitrogen uptake and plant carbon distribution directly affect shoots and roots. Increasing nitrogen supply stimulates biomass production on shoots and roots of cedar trees. Under natural conditions, nitrogen is one of the environmental factors that regulates the establishment of woody species (Boukcim et al., 2006; Wan et al., 2019).

Our findings expect a large decrease in the area occupied by the Atlas Cedar forests for the year 2070 (about $71.6-80.6 \%$ of the current range size). This is consistent with changes observed over the past inventories (Bouahmed et al., 2019). According to Boudy (1950), the area covered by Atlas Cedar forests in Algeria was about $300 \mathrm{~km}^{2}$, whereas Quézel (1998) mentioned a surface area of $200 \mathrm{~km}^{2}$. Modeling species suitable habitats may overestimate the range size compared to the field data, that involve more accurate measurement methods. Our results actually represent the number of pixels with suitable conditions for the occurrence of the Atlas Cedar, although each of these $1-\mathrm{km}$-resolution pixels contains variable number 
of cedar trees (at least one) thus with variable vegetation cover. Nevertheless, comparing the same type of data over time provide reliable information about vegetation dynamics; thus our geostatistics are consistent in terms of the decrease of Atlas Cedar forests area over time. The comparison of maps of aridity conditions and the probability of Atlas Cedar occurrences for the present period and future scenarios shows the concordance of future pessimistic climate predictions with the regression in Atlas cedar distribution in northern Algeria.

The future dry and warm climatic conditions, marked large decrease of precipitation and an increase of the temperature, drought duration and intensity (Allen et al., 2010), seem to be the main causes of Atlas Cedar dieback at the lower limit of its range. High-altitude migration associated with latitudinal range shift northward the humid climates are more pronounced in species habitats with arid and semiarid conditions (Quézel, 1998; Rhanem, 2010; Bouahmed et al., 2019). Drought triggers species shift towards high altitudes to look for favorable habitats. However, those species with low dispersion capacity are threatened by gradual range shrinkage that may results in a species extinction (Rhanem 2010; Abel-Schaad et al., 2018; Malcolm et al., 2006; Gonzalez et al., 2010). For North African forests, a latitudinal shift towards the North is expected as a direct consequence of the rapid advance of aridity within the narrow band between the Mediterranean Sea in the North and the Sahara Desert in the South (Arar et al., 2009; Tabet et al., 2018; Zeroual et al., 2019). Furthermore, our results expect a clear longitudinal shift of Atlas cedar range from West to East. Eastern Algeria has a greater potential of cedar presence compared to the West, which could be mainly attributed to the favorable climatic conditions for the growth and regeneration of the species, in other words the aridity to the west of the country is more severe compared to the eastern part where Atlas cedars can persist in the face of various perils as well as to succeed in reproduction and thus ensure the sustainability of stands.

\section{Conclusion}

Ecological niches of the Atlas Cedar in Algeria were explored to determine the environmental variables that control current habitats of species potential distribution. SDM using MaxEnt revealed that species range could be confined to montane habitats as scattered populations in north of Algeria. Cedrus atlantica rage size is estimated at 2089 $\mathrm{km}^{2}$. Our findings reveal that the impacts of future climate change on Cedrus atlantica forests would be high as significant decreases in the spatial distribution through species favorable habitats was furcated for 2070. Significant decrease in suitable habitats is expected in Cedrus atlantica range, where the species is predicted to move towards areas with wetter conditions i.e. high elevations, northward the coastal areas with humid and mesic climate, and eastward that is more suitable that the west of Algeria. Results of this study enrich the existing information on the state of North African forests and constitute a mean for supporting decision-making in the sector of nature conservation. The ecological situation of Atlas Cedar forests urges for the necessity of an urgent intervention and planned management.

\section{References}

Abel-Schaad D., Iriarte E., López-Sáez J.A., Pérez-Díaz S., Sabariego Ruiz S., Cheddadi R. \& Alba-Sánchez F., 2018, Are Cedrus atlantica forests in the Rif Mountains of Morocco heading towards local extinction? The Holocene 28(6): 1023-1037. https://doi. org/10.1177/0959683617752842

Allen C.D., Macalady A.K., Chenchouni H., Bachelet D., McDowell N., Vennetier M., Kitzberger T., Rigling A., Breshears D.D., Hogg E.H.(T.), Gonzalez P., Fensham R., Zhang Z., Castro J., Demidova N., Lim J.-H., Allard G., Running S.W., Semerci A. \& Cobb N., 2010, A global overview of drought and heat-induced tree mortality reveals emerging climate change risks for forests. Forest Ecology and Management 259(4): 660-684. https://doi.org/10.1016/j.foreco.2009.09.001

Amici V., Marcantonio M., La Porta N. \& Rocchini D., 2017, A multi-temporal approach in MaxEnt modelling: a new frontier for land use/land cover change detection. Ecol. Inform. 40: 40-49. https://doi.org/10.1016/j. ecoinf.2017.04.005

Aoubouazza M., 2018, Estimation des besoins en eau du Cèdre à Ras El Ma et à Boutrouba (Moyen Atlas Central tabulaire). Revue Marocaine des Sciences Agronomiques et Vétérinaires 6(1): 36-47.

Arar A., Chenchouni H. \& Benabderrahmane M.C., 2009, Climate change and desertification risks assessment in Aurès region (Eastern of Algeria) by using of Geomatic data. Presentation at the Int. Joint Assembly of IAMAS-IAPSO-IACS “MOCA-2009”, Montreal, Canada.

Arar A., Tabet S., Nouidjem Y., Bounar R. \& Chenchouni H., 2019, Projected small-scale range reductions of Cedrus atlantica forests due to climate change at the Belezma National Park (Algeria), [in:] H. Chenchouni, E. Errami, F. Rocha, L. Sabato (eds). Exploring the Nexus of Geoecology, Geography, Geoarcheology and Geotourism. Springer, Cham: 15-19. https://doi. org/10.1007/978-3-030-01683-8_4

Booth T.H., Nix H.A., Busby J.R. \& Hutchinson M.F., 2014, BioClim: the first species distribution modelling package, its early applications and relevance to most 
current MaxEnt studies. Diversity and Distributions 20(1): 1-9. https://doi.org/10.1111/ddi.12144

Bouahmed A., Vessella F., Schirone B., Krouchi F. \& Derridj A., 2019, Modeling Cedrus atlantica potential distribution in North Africa across time: new putative glacial refugia and future range shifts under climate change. Regional Environmental Change 19: 16671682. https://doi.org/10.1007/s10113-019-01503-w

Boudy P., 1950, Economie forestière Nord-Africaine, Tomme 2 Monographie et traitement des essences forestières. Fasc II. Ed. Larousse, Paris.

Boukcim H., Pagès L. \& Mousain D., 2006, Local $\mathrm{NO}_{3}{ }^{-}$ or $\mathrm{NH}_{4}^{+}$supply modifies the root system architecture of Cedrus atlantica seedlings grown in a split-root device. Journal of Plant Physiology 163(12): 1293-1304. https://doi.org/10.1016/j.jplph.2005.08.011

Cheddadi R., Fady B., François L., Hajari L., Suc J.P., Huang K., Demarteau M, Vendramin G.G. \& Ortu E., 2009, Putative glacial refugia of Cedrus atlantica deduced from Quaternary pollen records and modern genetic diversity. Journal of Biogeography 36: 1361-1371. https://doi.org/10.1111/j.1365-2699.2008.02063.x

Cheddadi R., Henrot A. J., François L., Boyer F., Bush M., Carré M., Coissac E., De Oliveira P.E., Ficetala F., Hambuckers A., Huang K., Lézine A.-M., Nourelbait M., Rhoujjati A., Taberlet P., Sarmiento F., Abel-Schaad D., Alba-Sánchez F. \& Zheng Z., 2017, Microrefugia, climate change, and conservation of Cedrus atlantica in the Rif Mountains, Morocco. Frontiers in Ecology and Evolution 5: art. 114. https://doi.org/10.3389/ fevo.2017.00114

Chenchouni H., 2010, Drought-induced mass mortality of Atlas Cedar forest (Cedrus atlantica) in Algeria, [in:] J.A. Parrota, M.A. Carr (eds), The International Forestry Review, 33th IUFRO World Congress. 23-28 August 2010, Seoul, Korea.

Chenchouni H., 2017, Edaphic factors controlling the distribution of inland halophytes in an ephemeral salt lake "Sabkha ecosystem" at North African semi-arid lands. Science of Total Environment 575: 660-671. https://doi. org/10.1016/j.scitotenv.2016.09.071

Chenchouni H., Abdelkrim S.B. \& Athmane B., 2008, The deterioration of the Atlas Cedar (Cedrus atlantica) in Algeria. Proceednigs of international conference "Adaptation of forests and forest management to changing climate with emphasis on forest health: a review of science, policies, and practices", Umeå, Sweden, pp. 25-28. Swedish University of Agricultural Sciences (SLU), FAO \& IUFRO.

Choat B., Jansen S., Brodribb T.J., Cochard H., Delzon S., Bhaskar R., Bucci S.J. Feild T.S., Gleason S.M., Hacke U.G., Jacobsen A.L. Lens F., Maherali H., Martinez-Vilalta J., Mayr S., Mencuccini M., Mitchell P. J., Nardini A., Pittermann J., Pratt R.B., Sperry J.S.,
Westoby M., Wright I.J. \& Zanne A.E., 2012, Global convergence in the vulnerability of forests to drought. Nature 491(7426): 752-755. https://doi.org/10.1038/nature 11688

Elith J., Phillips S.J., Hastie T., Dudik M., Chee Y.E. \& Yates C.J., 2011, A statistical explanation of MaxEnt for ecologists. Diversity and Distribution 17: 43-57. https://doi.org/10.1111/j.1472-4642.2010.00725.x

Ezzahiri M. \& Belghazi B., 2000, Synthèse de quelques résultats sur la régénération naturelle du cèdre de l'Atlas au Moyen Atlas (Maroc). Sécheresse 11 (2): 79-84.

Fois M., Cuena-Lombraña A., Fenu G., Cogoni D. \& Bacchetta G., 2016, The reliability of conservation status assessments at regional level: past, present and future perspectives on Gentiana lutea L. ssp. lutea in Sardinia. J. Nat. Conserv. 33: 1-9. https://doi.org/10.1016/j. jnc.2016.06.001

Garcia R.A., Burgess N.D., Cabeza M., Rahbek C. \& Araújo M.B., 2012, Exploring consensus in 21st century projections of climatically suitable areas for African vertebrates. Global Change Biology 18(4): 1253-1269. https://doi.org/10.1111/j.1365-2486.2011.02605.x

Gonzalez P., Neilson R.P., Lenihan J.M. \& Drapek R.J., 2010 , Global patterns in the vulnerability of ecosystems to vegetation shifts due to climate change. Global Ecology and Biogeography 19(6): 755-768. https://doi. org/10.1111/j.1466-8238.2010.00558.x

Graham J. \& Kimble M., 2019, Visualizing uncertainty in habitat suitability models with the hyper-envelope modeling interface, version 2. Ecology and Evolution 9(1): 251-264. https://doi.org/10.1002/ece3.4720

Guisan A., Thuiller W. \& Zimmermann N.E., 2017, Habitat Suitability and Distribution Models. With Applications in R. Cambridge University Press, Cambridge. https:// doi.org/10.1017/9781139028271

Guisan A. \& Zimmermann N.E., 2000, Predictive habitat distribution models in ecology. Ecological Modelling 135(2-3): 147-186. doi: https://doi.org/10.1016/ S0304-3800(00)00354-9

Hansen W.D., Braziunas K.H., Rammer W., Seidl R. \& Turner M.G., 2018, It takes a few to tango: changing climate and fire regimes can cause regeneration failure of two subalpine conifers. Ecology 99(4): 966-977. https://doi.org/10.1002/ecy.2181

Hijmans R.J., Cameron S.E., Parra J.L., Jones P.G. \& Jarvis A., 2005, Very high resolution interpolated climate surfaces for global land areas. International Journal of Climatology 25: 1965-1978. doi: 10.1002/joc.1276

IPCC, 2014, Climate Change 2014: Synthesis Report, [in:] Core Writing Team, R.K. Pachauri and L.A. Meyer (eds), Contribution of Working Groups I, II and III to the Fifth Assessment Report of the Intergovernmental Panel on Climate Change. IPCC, Geneva, Switzerland, $151 \mathrm{pp}$. 
Khanfouci M.S., 2005, Contribution à l'étude de la fructification et de la régénération du cèdre de l'Atlas (Cedrus atlantica Manetti) dans le massif du Belezma. Dissertation, Univ. Batna, Algeria.

Knippertz P., Christoph M. \& Speth P., 2003, Long-term precipitation variability in Morocco and the link to the large-scale circulation in recent and future climates. Meteorology and Atmospheric Physics 83(1-2): 67-88. https://doi.org/10.1007/s00703-002-0561-y

Legendre P. \& Legendre L., 1998, Numerical ecology. Second English edition. Elsevier Science BV, Amsterdam, The Netherlands.

Legendre P. \& Fortin M.J., 1989, Spatial pattern and ecological analysis. Vegetatio 80: 107-138. https://doi. org/10.1007/BF00048036

Linares J.C., Taïqui L. \& Camarero J.J, 2011, Increasing drought sensitivity and decline of Atlas Cedar (Cedrus atlantica) in the Moroccan Middle Atlas forests. Forests 2(3): 777-796. https://doi.org/10.3390/f2030777

Malcolm J.R., Liu C., Neilson R.P., Hansen L. \& Hannah L.E.E., 2006, Global warming and extinctions of endemic species from biodiversity hotspots. Conservation Biology 20(2): 538-548. https://doi.org/10.1111/j.15231739.2006.00364.x

McDowell N.G. \& Allen C.D., 2015, Darcy's law predicts widespread forest mortality under climate warming. Nature Climate Change 5(7) : 669-672. https://doi. org/10.1038/nclimate2641

Navarro-Cerrillo R.M., Sarmoum M., Gazol A., Abdoun F. \& Camarero J.J., 2019, The decline of Algerian Cedrus atlantica forests is driven by a climate shift towards drier conditions. Dendrochronologia 55: 60-70. https:// doi.org/10.1177/0959683617752842

Patil I. \& Powell C., 2018, ggstatsplot: 'ggplot2' based plots with statistical details. https://doi.org/10.5281/ zenodo.2074621, https://CRAN.R-project.org/ package $=$ ggstatsplot

Phillips S.J., Anderson R.P. \& Schapire, R.E., 2006, Maximum entropy modeling of species geographic distributions. Ecological Modelling 190(3): 231-259. https:// doi.org/10.1016/j.ecolmodel.2005.03.026

Quézel P., 1976, Les forêts du pourtour méditerranéen, [in:] Forêts et maquis méditerranéens: Écologie, Conservation et Aménagement. Notes techniques du MAB. Presse de l'Unesco, Paris: 9-33.

Quézel P., 1998, Cèdres et cédraies du pourtour méditerranéen: signification bioclimatique et phytogéographique. Forêt méditerranéenne 19: 234-260.

Rhanem M., 2010, Esquisse d'une typologie géomorphologiques de quelques cédraies à Cedrus atlantica Man. dans le Haut Atlas oriental de Midelt (Maroc). Menaces et perspectives de conservation, de gestion et de restauration. Quad. Bot. Amb. Appl. 21: 141-159.

Safaei M., Tarkesh M., Bashari H. \& Bassiri M., 2018, Modeling potential habitat of Astragalus verus Olivier for conservation decisions: a comparison of three correlative models. Flora 242: 61-69. https://doi. org/10.1016/j.flora.2018.03.001

Sequeira C.H. \& Alley M.M., 2011, Soil organic matter fractions as indices of soil quality changes. Soil Science Society of America Journal 75(5): 1766-1773. doi:10.2136/sssaj2011.0067

Silvertown J., 2004, Plant coexistence and the niche. Trends Ecol. Evol. 19: 605-611. https://doi.org/10.1016/j. tree.2004.09.003

Slimani S., 2014, Reconstitutions dendrochronologiques du climat et de l'historique des incendies dans les régions des Aurès et de Kabylie, nord de l'Algérie. Doctoral thesis, Univ. Tizi-Ouzou, Algeria.

Tabet S., Arar A., Merdas S. \& Chenchouni H., 2019, Soil available water capacity in Algeria: mapping and modeling current conditions and projected changes under future IPCC global climate change scenarios. (unpublished).

Tabet S., Belhemra M., Francois L. \& Arar A., 2018, Evaluation by prediction of the natural range shrinkage of Quercus ilex L. in eastern Algeria. Forestist 68(1): 7-15. https://doi.org/10.5152/forestist.2018.002

Thomas P., 2013, Cedrus atlantica. The IUCN Red List of Threatened Species 2013: e.t42303a2970716. http://dx.doi.org/10.2305/iucn.uk.2013-1.rlts. t42303a2970716.en

Touchan R., Anchukaitis K.J., Meko D.M., Sabir M., Attalah S. \& Aloui A., 2011, Spatiotemporal drought variability in northwestern Africa over the last nine centuries. Climate Dynamics 37: 237-252. https://doi. org/10.1007/s00382-010-0804-4

Walther G.R., Post E., Convey P., Menzel A., Parmesan C., Beebee T.J., Fromentin J.M., Hoegh-Guldberg O. \& Bairlein F., 2002, Ecological responses to recent climate change. Nature 416(6879): 389-395. https://doi. org/10.1038/416389a

Wan J.Z., Yu J.H., Yin G.J., Song Z.M., Wei D.X. \& Wang C.J., 2019, Effects of soil properties on the spatial distribution of forest vegetation across China. Global Ecology and Conservation 18: e00635. https://doi. org/10.1016/j.gecco.2019.e00635

Williams K.J., Belbin L., Austin M.P., Stein J.L. \& Ferrier S., 2012, Which environmental variables should I use in my biodiversity model?. International Journal of Geographical Information Science 26(11): 2009-2047. doi: https://doi.org/10.1080/13658816.2012.698015

Zeroual A., Assani A.A., Meddi M. \& Alkama R., 2019, Assessment of climate change in Algeria from 1951 to 2098 using the Köppen-Geiger climate classification scheme. Climate Dynamics 52(1-2): 227-243. https:// doi.org/10.1007/s00382-018-4128-0

Zhang Z., Xu, S., Capinha C., Weterings R. \& Gao T., 2019, Using species distribution model to predict the impact of climate change on the potential distribution of Japanese whiting Sillago japonica. Ecol. Indic. 104: 333-340. https://doi.org/10.1016/j.ecolind.2019.05.023 
Table S1. Contributions of the 32 explanatory environmental variables used in ecological niche modeling of potential distribution of Atlas Cedar (Cedrus atlantica) forests in Algeria

\begin{tabular}{|c|c|c|c|c|}
\hline $\begin{array}{l}\text { ariable } \\
\text { category }\end{array}$ & $\begin{array}{l}\text { Variable } \\
\text { code }\end{array}$ & Variable description & Source & $\begin{array}{c}\text { Contribution } \\
{[\%]}\end{array}$ \\
\hline Edaphic & NTO & Total nitrogen soil $[\mathrm{g} / \mathrm{kg}]$ & SoilGrids & 22.2 \\
\hline Topographic & Alt & Altitude $[\mathrm{m}]$ & $\begin{array}{l}\text { Derived from } \\
\text { DEM }\end{array}$ & 20.5 \\
\hline Climatic & Bio8 & Mean temperature of wettest quarter $\left[{ }^{\circ} \mathrm{C}\right]$ & WorldClim & 18.8 \\
\hline Topographic & Slope & Slope $[\%]$ & $\begin{array}{l}\text { Derived from } \\
\text { DEM }\end{array}$ & 12.9 \\
\hline Edaphic & CTO & Total soil carbone $[\mathrm{g} / \mathrm{kg}]$ & SoilGrids & 10.3 \\
\hline Climatic & Bio14 & Precipitation of driest month [mm] & WorldClim & 3.4 \\
\hline Climatic & Bio4 & Temperature seasonality (standard deviation $\times 100$ ) & WorldClim & 2.6 \\
\hline Edaphic & AWC_spr & Spring soil available water capacity $[\mathrm{mm}]$ & Computed & 1.6 \\
\hline Edaphic & Bulk_dens & Bulk density (fine earth) $\left[\mathrm{kg} / \mathrm{m}^{3}\right]$ & SoilGrids & 1.3 \\
\hline Climatic & Bio3 & Isothermality (Bio2/Bio7) $(\times 100)$ & WorldClim & 0.8 \\
\hline Topographic & Distance_sea & Distance to the sea $[\mathrm{m}]$ & $\begin{array}{l}\text { Derived from } \\
\text { DEM }\end{array}$ & 0.7 \\
\hline Edaphic & Clay & Soil texture fraction: Clay [\%] & SoilGrids & 0.5 \\
\hline Edaphic & K_Exchang & Exchangeable $\mathrm{K}^{+}[\mathrm{cmol}+/ \mathrm{kg}]$ & SoilGrids & 0.5 \\
\hline Edaphic & Mg_Exchang & Exchangeable $\mathrm{Mg}^{++}[\mathrm{cmol}+/ \mathrm{kg}]$ & SoilGrids & 0.4 \\
\hline Edaphic & $\mathrm{pH}$ & Potential hydrogen & SoilGrids & 0.4 \\
\hline Edaphic & Sand & Soil texture fraction: Sand [\%] & SoilGrids & 0.4 \\
\hline Climatic & Bio16 & Precipitation of wettest quarter [mm] & WorldClim & 0.3 \\
\hline Edaphic & AWC_summ & Summer soil available water capacity [mm] & Computed & 0.3 \\
\hline Edaphic & CEC & Cation exchange capacity [cmolc/kg] & SoilGrids & 0.3 \\
\hline Edaphic & Porosity & Porosity [\%] & SoilGrids & 0.3 \\
\hline Topographic & Rad_summ & Global radiation during summer $\left[\mathrm{Wh} / \mathrm{m}^{2}\right]$ & $\begin{array}{l}\text { Derived from } \\
\text { DEM }\end{array}$ & 0.3 \\
\hline Topographic & Rad_spring & Global radiation during spring $\left[\mathrm{Wh} / \mathrm{m}^{2}\right]$ & $\begin{array}{l}\text { Derived from } \\
\text { DEM }\end{array}$ & 0.3 \\
\hline Climatic & Bio2 & $\begin{array}{l}\text { Mean diurnal range (mean of monthly (max temp }-\min \\
\text { temp)) }\left[{ }^{\circ} \mathrm{C}\right]\end{array}$ & WorldClim & 0.2 \\
\hline Climatic & Bio6 & Min temperature of coldest month $\left[{ }^{\circ} \mathrm{C}\right]$ & WorldClim & 0.2 \\
\hline Climatic & Bio15 & Precipitation seasonality (coefficient of variation) & WorldClim & 0.1 \\
\hline Climatic & Bio9 & Mean temperature of driest quarter $\left[{ }^{\circ} \mathrm{C}\right]$ & WorldClim & 0.1 \\
\hline Edaphic & Ca_Echang & Exchangeable $\mathrm{Ca}^{++}[\mathrm{cmol}+/ \mathrm{kg}]$ & SoilGrids & 0.1 \\
\hline Topographic & Aspect & Aspect & $\begin{array}{l}\text { Derived from } \\
\text { DEM }\end{array}$ & 0.1 \\
\hline Edaphic & $\mathrm{C} \_\mathrm{N}$ & Carbon/nitrogen Ratio (C/N ratio) & SoilGrids & $<0.1$ \\
\hline Edaphic & $\mathrm{CE}$ & Electrical conductivity $[\mathrm{dS} / \mathrm{m}]$ & SoilGrids & $<0.1$ \\
\hline Edaphic & $\mathrm{Na}$ _Echang & Exchangeable $\mathrm{Na}^{+}[\mathrm{cmol}+/ \mathrm{kg}]$ & SoilGrids & $<0.1$ \\
\hline Edaphic & BS & $\begin{array}{l}\text { Base saturation }(\%)=(\text { total exchangeable bases }[\mathrm{cmolc} / \\
\mathrm{kg}] / \mathrm{CEC})\end{array}$ & SoilGrids & $<0.1$ \\
\hline
\end{tabular}

DEM: Digital elevation model retrieved from ASTER GDEM version 2 (https://asterweb.jpl.nasa.gov/gdem-wist.asp). Generation \& Distribution: METI/ERSDAC/NASA/USGS

SoilGrids: https://SoilGrids.org

WorldClim: http://worldclim.org/version1 (Hijmans et al., 2005) 